\title{
Carbon Isotope Ratios in Carbon Stars of the Galactic Halo
}

\section{WAKO AOKI ${ }^{1,2}$ and TAKASHI TSUJI ${ }^{1}$}

${ }^{1}$ Institute of Astronomy, The University of Tokyo, Mitaka, Japan

2 Department of Astronomy, The University of Tokyo, Tokyo, Japan

We have analysed the $\mathrm{CN}$ red system $(\sim 8000 \AA)$ and the $\mathrm{C}_{2}$ Swan system $(\sim 4700 \AA)$ to obtain carbon isotope ratios $\left({ }^{12} \mathrm{C} /{ }^{13} \mathrm{C}\right)$ for carbon stars in the Galactic halo, known as $\mathrm{CH}$ stars. Isotope ratios are obtained for $6 \mathrm{CH}$ stars by a curve-of-growth analysis of isolated ${ }^{12} \mathrm{CN}$ and ${ }^{13} \mathrm{CN}$ lines. In this analysis, we directly compare ${ }^{12} \mathrm{CN}$ and ${ }^{13} \mathrm{CN}$ lines of similar intensity (isointensity method), and the resulting ${ }^{12} \mathrm{C} /{ }^{13} \mathrm{C}$ ratios are almost independent of the model atmosphere and its parameters. The ${ }^{13} \mathrm{CN}$ lines were too weak to measure in some $\mathrm{CH}$ stars, for which we applied the spectral synthesis method to the stronger $\mathrm{C}_{2}$ Swan band and obtained ${ }^{12} \mathrm{C} /{ }^{13} \mathrm{C}$ ratios for two stars and estimated a lower limit to the ${ }^{12} \mathrm{C} /{ }^{13} \mathrm{C}$ ratio for two others. In this case, however, the results depend on the model atmosphere and its parameters. Results from our present and previous work show that most $\mathrm{CH}$ stars (12 stars) have values distributed around ${ }^{12} \mathrm{C} /{ }^{13} \mathrm{C} \approx 10$ while two stars have very high values $\left({ }^{12} \mathrm{C} /{ }^{13} \mathrm{C} \geq 500\right)$. The distribution of the ${ }^{12} \mathrm{C} /{ }^{13} \mathrm{C}$ ratio in $\mathrm{CH}$ stars is different from those of the Population I carbon stars and Population II oxygen-rich giants ( $\mathrm{G}-\mathrm{K}$ types). The $\mathrm{CH}$ stars of very high ${ }^{12} \mathrm{C} /{ }^{13} \mathrm{C}$ ratio can be explained by dredge-up of ${ }^{12} \mathrm{C}$ due to the $3 \alpha$-process as in Population I carbon stars (N-type). On the other hand, the formation of $\mathrm{CH}$ stars with low ${ }^{12} \mathrm{C} /{ }^{13} \mathrm{C}$ ratios requires a large supply of ${ }^{12} \mathrm{C}$ followed by a process for decreasing the ${ }^{12} \mathrm{C} /{ }^{13} \mathrm{C}$ ratio. 